\title{
The Construction and Application of System Dynamic Model for Regional Logistics
}

\author{
FENG JinZhan ${ }^{1, \text { a }}$, CAO DanTing ${ }^{2}$ \\ ${ }^{1}$ Jiangxi College of Foreign Studies, Business Administration Department, Jiangxi, Nanchang \\ 330000, China

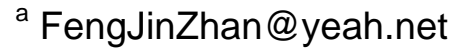

\section{Keywords: System Dynamic Model; Regional Logistics; Logistics system}

\begin{abstract}
With the continuous development of economic globalization and regional economic integration, the economic ties between the countries and regions are increasingly close, the economic cooperation between the regions has become a common economic phenomenon. The organic combination of the basic principle of system dynamics and modern logistics, probing into the new concept of regional logistics system dynamics and modeling method. According to the characteristics of the regional logistics system, the establishment of regional logistics system dynamics model, through the example of regional logistics system analysis, prove the model is practical and guiding significance, and proved that the established model of regional logistics system is the study of regional logistics problem is feasible and effective method.
\end{abstract}

\section{Introduction}

With the process of regional economic integration and economic globalization, people pay more and more attention to the development of regional logistics. The development of the regional logistics has become one of the important economic growth point of the regional economy and the pillar industry, its development level is the evaluation of regional modernization and an important indicator of comprehensive economic strength [1]. Logistic has become an important factor of economic development in our country, the logistics theory research in China still lags behind in comparison with economically developed countries. In the rapid economic development, economic increase total demand, the development of the logistics industry lack of systemic and integrated, the direction of the development of logistics industry in the local area position is not clear, practical significance for the lack of theoretical guidance, logistics market demand analysis and the actual situation of the gap[2].

The rationalization of regional logistics system research, in order to strengthen the regional logistics system to support regional economic development, improve overall comprehensive functions for the purpose of urban agglomeration. As the industrialization, big city or many thorny problems logistics development of urban agglomerations. Such as unreasonable industrial structure, traffic congestion, floating population growth, land and housing prices, etc. Due to the complexity of relevant factors is more, the traditional method is difficult to make a comprehensive analysis of the right. As a result, the application of system dynamics approach to a regional economic system research of logistics system, established the corresponding model, a comprehensive analysis of the region logistics related problem, make its internal energy over a longer period for quantitative analysis of the right of all the more necessary.

\section{The composition and modeling process of regional logistics system dynamics model}

Traditional management, organization theory, and all kinds of system in order to establish the corresponding basic theory model to provide information, experience and judgment, when its fusion can be extracted with feedback theory system dynamics model of the system [3]. Modern computer simulation technology to provide cheap, powerful means of the simulation calculation, we can easily according to the model analysis the dynamic behavior of the system, evaluation policy, so as 
to achieve the purpose of selection in policy analysis. Dynamic model of regional logistics system is shown in figure 1.

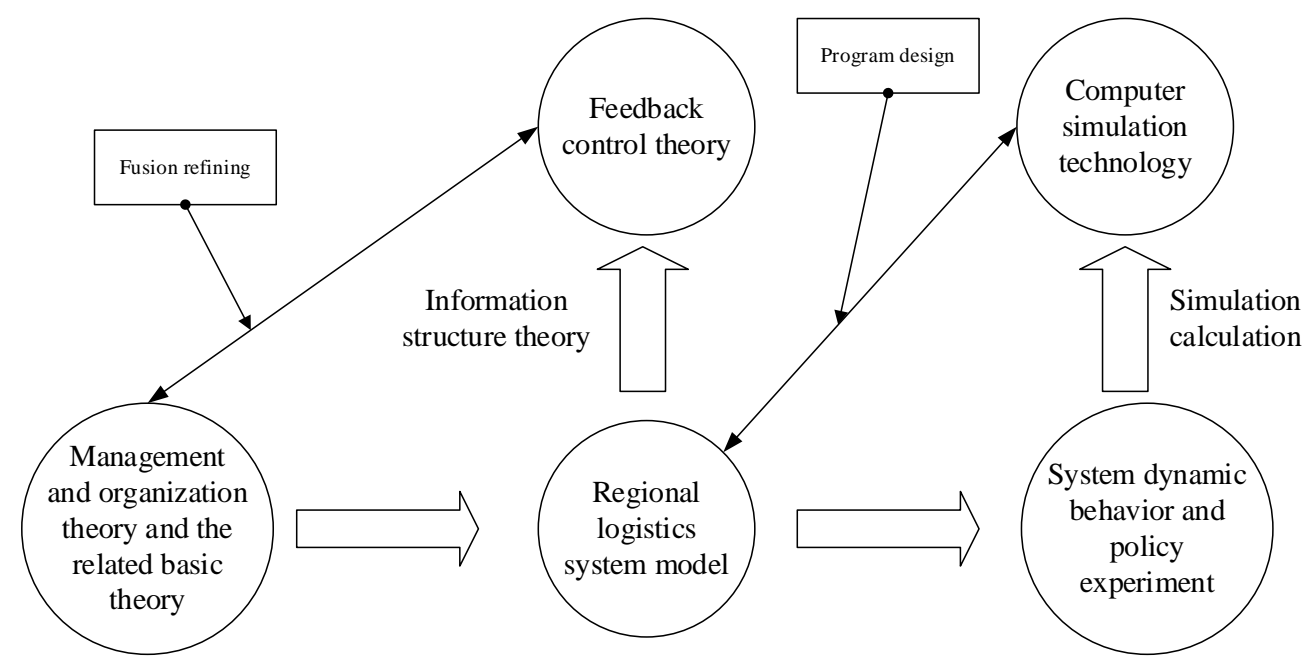

Figure 1. The composition of regional logistics system dynamics model

According to system dynamics modeling steps, can draw the basic process of system dynamics research, is divided into six stages: problem definition, conceptual model, mathematical expression, model simulation, evaluation and policy analysis. The problem definition and conceptual model are two technical weaker in system dynamics research stage, in the second stage, for clarify the content and features, outline the system reference model, clear the purpose of modeling, the system boundary is determined, in accordance with the behavior and information feedback loops determine system structure. The model, simulation and policy analysis for representation of the three stages of complete according to the feedback structure with chateau DYNAMO language expression model, observation model behavior and behavior according to relevant statistics evaluation of fitting degree. Policy analysis is carried through the effect degree of for its social and economic development.

\section{The establishment of the regional logistics system dynamics model}

Study and simulation on the regional logistics system, the first thing to understand the actual background of the problem, the requirements of specific research object at the same time, the construction of regional logistics system dynamics model of the purpose is to science and intuitive reflect the logistics process and effect, and different logistics strategy differences impact on the system [4-5]. Regional logistics system model to consider the main factors, ignoring secondary factors in the system, makes the model simple and clear and compelling, beneficial to model was understood, is helpful to adopt various methods to study the different link of regional logistics. Regional logistics system can be divided into five modules: economic growth structure, whole structure, consumption structure, and logistics demand structure and logistics capability. According to the above module, and on the analysis of the regional logistics system, based on the basic causation can be concluded dynamics model of regional logistics system as shown in figure 2 .

Therefore, it need from different angles, a comprehensive analysis and study on the regional logistics system, at the same time, the need to pay attention to the research of gradation, only in this way can overcome complex tedious work, find out the method to solve the problem, better hierarchical analysis is beneficial to our in-depth understanding of regional logistics process, strengthen the understanding of the relationship between regional logistics each link. Understand internal structure and dynamic behavior characteristics of regional logistics system, deepen the understanding of the nature of regional logistics system, and use it for logistics planning and policy simulation of actual economic development role. 


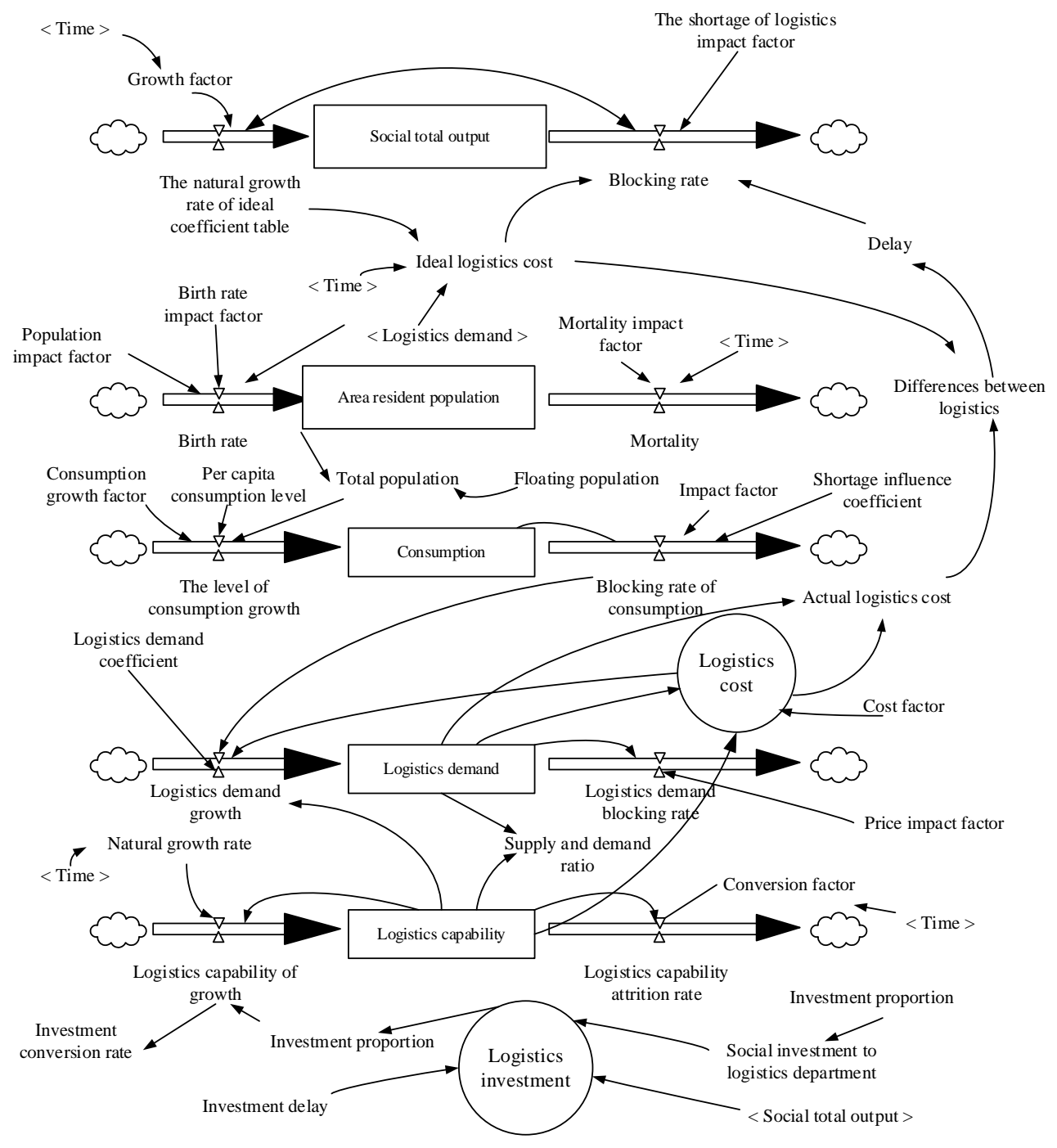

Figure 2. The regional logistics system dynamics model

\section{The application of regional logistics system dynamics model}

Here in some areas of China as the research object, for calculation and simulation data of the region, according to the result of calculation and simulation to analyze the structure and characteristics of the regional logistics model. The region the mathematic expression of the regional logistics system dynamics model of the initial value listed in table 1.

Table 1. Initial values of the mathematic al equation (in 1999)

\begin{tabular}{c|c}
\hline Variable & Initial value \\
\hline Social total output & 643990 \\
\hline Area resident population & 2262.14 \\
\hline Consumption & 248704 \\
\hline Logistics demand & 78456 \\
\hline Logistics capability & 39748
\end{tabular}

Listed in table 1 will be the initial value in $X(t 0)=X(0)$, it can get:

$$
\boldsymbol{X}\left(t_{0}\right)=\boldsymbol{X}(0)=\left[\begin{array}{cc}
643 & 990 \\
2 & 262.14 \\
248 & 704 \\
78 & 456 \\
39 & 748
\end{array}\right]
$$




$$
\boldsymbol{X}(t)=\Phi(t) \boldsymbol{X}(0)=\left[\begin{array}{l}
643900 R_{11}+2262.14 R_{12}+248704 R_{13}+78456 R_{14}+39748 R_{1} \\
643900 R_{21}+2262.14 R_{22}+248704 R_{23}+78456 R_{24}+39748 R_{2} \\
643900 R_{31}+2262.14 R_{32}+248704 R_{33}+78456 R_{34}+39748 R_{3} \\
643900 R_{41}+2262.14 R_{42}+248704 R_{43}+78456 R_{44}+39748 R_{44} \\
643900 R_{51}+2262.14 R_{52}+248704 R_{53}+78456 R_{54}+39748 R_{53}
\end{array}\right.
$$

Social total output of the simulation results are shown in figure 4 (a). By the simulation results can be seen that social total output in the area of the pearl river delta in 1999, after 20 years will continue to rise, due to the base of social output value is more and more big, the economic growth is bigger and bigger. The logistics demand change, the simulation results as shown in figure 4 (b), the pearl river delta regional logistics demand is bigger and bigger, this is the requirement of social and economic development on the one hand, on the other hand is because with the development of the logistics supply and demand balance gradually. Logistics supply capacity of the simulation results as shown in figure 4 (c), by the simulation results can be seen that the logistics supply capacity in 1999 after 20 years will continue to rise, due to the social demand for logistics is increasing year by year, so logistics supply capacity must also constantly improve, don't a serious impediment to the development of social economy. Logistics costs of the simulation curve as shown in figure 4 (d), logistics costs in general is on the decline, as the play of social investment effect and the improvement of logistics supply capacity, logistics cost will be more and more small, this is in accordance with the wishes of the development of society.
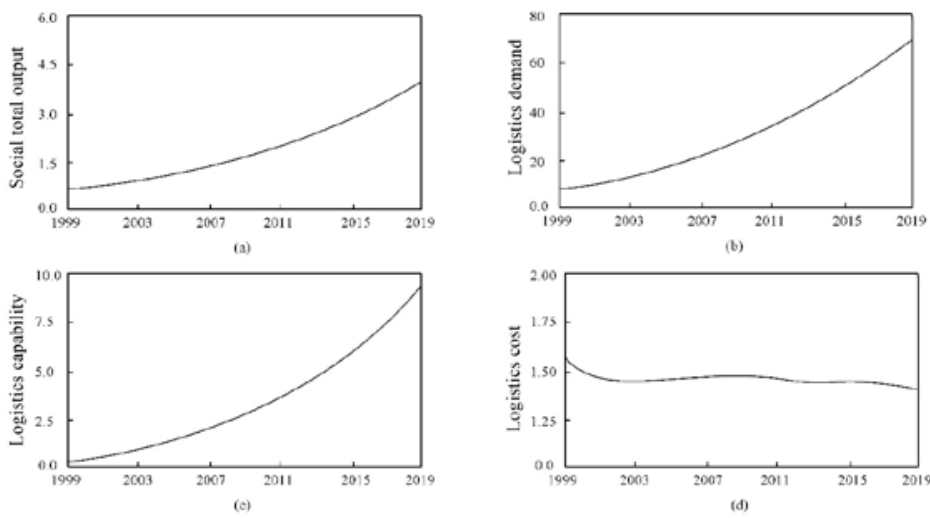

Figure 3. Simulation results

\section{Conclusion}

Regional logistics system dynamics model provides a new research method, is advantageous for the related decision institutions and relevant departments according to the theoretical analysis of this article combined with the actual status, the system structure is complex, historical data under the condition of less, regional logistics system dynamics model is established. By establishing a system dynamics model of regional logistics for regional logistics system simulation and the analysis of the policy. Especially in the complex system structure, the historical data under the condition of less, can understand the internal structure and dynamic behavior characteristics of regional logistics system, deepen the understanding of the nature of regional logistics system, and can use it as a policy simulation train of thought, the theoretical basis of the irreplaceable role with other methods.

\section{Acknowledgements}

Humanity and Social Science Youth foundation of Education Department of Jiangxi, JJ1348."Optimization of the internal structure of the logistics industry under the energy crisis environment from the analysis of deconstruction." 


\section{Referencess}

[1] G. Luo, C. Yin, and X. Chen: Ecological Complexity, Vol.7 (2010) No.2, p. 198

[2] A. Wilson: Catastrophe Theory and Bifurcation (Routledge Revivals): Applications to Urban and Regional Systems [M]. Routledge, 2012.

[3] J. Han, Y. Hayashi, and X. Cao: Landscape and Urban Planning, Vol.91 (2011) No.3, p. 133.

[4] M.L. Lin, C.W. Chen: Engineering Computations, Vol.27 (2010) No.1, p. 5.

[5] Q. Shen, Q. Chen, B. Tang: Habitat International, Vol.33 (2011) No.1, p. 15 